\section{SAFEGUARDS FOR DOCTORS REFERENCE TO MEDICAL NEGLIGENCE}

\author{
Srivastava C. P \\ Address for Correspondence:- \\ Dr. C. P. Srivastava \\ Associate Professor of Paediatrics \\ U.C.M.S. Teaching Hospital Ranigaon, \\ Bhairahawa, Nepal. \\ Email :- drcpsrivastava@yahoo.com
}

Doctors were taken next to God in the past. At present, they are only skilled service provider. In a seller- buyer system today, the awareness of patients has gone up and litigation cases against doctors are on rise.

There cannot be any smoke without fire. Thus medical negligence does occur due to one or the other reason. To err is human but the Medical profession has to be a zero error profession as it deals human beings directly.

SUMMARY OF PROPHYLACTIC MEASURES to be taken by doctors to avoid medical negligence and litigations are as under:

Follow the policy "PREVENTION IS BETTER THAN CURE" The points are as under:
1. Adequate and update knowledge is a must priority for reasonable care.

2. Doctor's profession is ought to be ZERO ERROR activities.

3. The subordinates must be trained adequately to avoid vicarious liability of errors.

4. Adequate communication skill has to be practiced. The skill has to be developed leaving aside ego and arrogance.

5. Writing work has to be proper and update because this is going to be a first hand protective tool in case of litigations. Record keeping is important including specific and proper consents.

6. Even a very busy doctor has to spend time for communication with the patient/relatives. This can be done by seeing and doing limited work. With unlimited patients either in outdoor or indoor or procedures including surgery operations; the chance of negligence obviously increases.

7. Prescription writing has to be in proper form.

8. Indemnity insurance is a must.

9. Rationale prescription of drugs is essential. Warn the patient with adverse side effects. For rational drug therapy, weight of the patient is important and is an absolute must in children patients.

10. Proper record keeping must be ensured.(may be computerized)

11. Mention the disagreement of the patient or close relatives (spouse) for their refusal regarding treatment or procedures of investigations. This will be 
to establish collateral or third party negligence.

12. Indoor/ anaesthesia/ preoperative/post-operative and follow up notes must be adequate.

13. Second opinion of a specialist is always safe.

14. Advise all necessary investigations whether the patient's pocket permits it or not. In case of refusal record this.

15. During referral, insure proper first aid and proper referral notes.

16. Emergency tray with essential medicines is a must.

17. It is better to get the hospital also insured.

18. Do not criticize/comment adversely other doctor.

19. Allow spouse/blood relatives to see/meet the patient, when you guess patient is going to die soon. This is a great emotional event and the hospital rules have to be relaxed for such situations on humanitarian grounds.

20. In adverse situations inform police for adequate protection and action.

21. Keep ready reckoner books for references including internet facility.

22. In time of trouble inform the indemnity insurance co. and consult your counsel.

23. Ethics and moral of the profession has to be observed.

24. While dealing the patient, empathy and sympathy both are required.

25. Be willing to apologize or admit a mistake other than a negligence.
26. While explaining a prognosis, do not give false hope and assurance. Encourage patient to ask questions.

27. While dealing an agitated patient, keep your head cool.

28. Be tactful and extra careful while dealing with any mob or press/media persons.

29. If something can be done for patient care, it must be done. "As long as there is life, there is hope"

30. Quality medical facilities are expensive, but then you have to pay a price for the best. 